Pacific Journal of Mathematic 


\title{
THE SCHWARZIAN DERIVATIVE AND MULTIVALENCE
}

\author{
W. J. KIM
}

A generalization of the Schwarzian derivative and a sufficient condition for disconjugacy of the $n$ th-order differential equation with analytic coefficients are obtained. These results are then used to establish a multivalence criterion for a certain family of analytic functions.

Let $y_{1}$ and $y_{2}$ be linearly independent solutions of the differential equation

$$
y^{\prime \prime}+p(z) y=0
$$

and let

$$
w=\frac{y_{2}}{y_{1}}
$$

Then, by a classical formula,

$$
p=\frac{1}{2}\{w, z\}
$$

where $\{w, z\}$ is the Schwarzian derivative of $w$, i.e.,

$$
\{w, z\}=\left(\frac{w^{\prime \prime}}{w^{\prime}}\right)^{\prime}-\frac{1}{2}\left(\frac{w^{\prime \prime}}{w^{\prime}}\right)^{2} .
$$

Conversely, the general solution $w$ of (1.3) is of the form (1.2).

Utilizing the above relations, Nehari [5] proved that for an analytic function $f$ to be univalent in the unit disk $D=\{z:|z|<1\}$ it is necessary that

$$
|\{f, z\}| \leqq \frac{6}{\left(1-|z|^{2}\right)^{2}}, \quad z \in D
$$

and sufficient that

$$
|\{f, z\}| \leqq \frac{2}{\left(1-|z|^{2}\right)^{2}}, \quad z \in D
$$

Generalizations of formula (1.3) for higher-order differential equations have recently been obtained. Vodicka [9] considered the $n$ thorder equation of the type

$$
y^{(n)}+p(z) y=0
$$

and derived a relation between the coefficient $p$ and the function $w=$ 
$y_{2} / y_{1}$, where $y_{1}$ and $y_{2}$ are any two linearly independent solutions of (1.4). In a recent paper, Lavie [4] established relations between the coefficients of the differential equation

$$
y^{(n)}+p_{n-1}(z) y^{(n-1)}+\cdots+p_{0}(z) y=0
$$

and the function $w=y_{2} / y_{1}$, where $y_{1}$ and $y_{2}$ are certain linearly independent solutions of (1.5).

In $\S 2$ we shall consider the $n$ th-order differential equation (1.5) and derive relations in which each coefficient $p_{i}$ is expressed as a function of the ratios $y_{i} / y_{n}, i=1,2, \cdots, n-1$, where $y_{1}, y_{2}, \cdots, y_{n}$ are linearly independent solutions of (1.5).

In $\S 3$, using the relations derived in $\S 2$, we establish a sufficient condition for $p$-valence of a $p$-parameter family of analytic functions.

2. In this section we shall obtain some invariants which play a role in the study of differential equation

$$
y^{(n)}+p_{n-2}(z) y^{(n-2)}+\cdots+p_{0}(z) y=0
$$

which is analogous to that played by (1.3) in the study of (1.1). We remark that there is no loss of generality in considering (2.1) because any homogeneous $n$ th-order linear differential equation can be put into the form (2.1) by a standard transformation.

Let $y_{i}, i=1,2, \cdots, n$, be linearly independent solutions of (2.1) and set

$$
f_{1}=\frac{y_{1}}{y_{n}}, \cdots, f_{n-1}=\frac{y_{n-1}}{y_{n}} .
$$

We seek relations of the type

$$
p_{i}=\Phi_{i}\left(f_{1}, f_{2}, \cdots, f_{n-1}\right), i=0,1, \cdots, n-2 .
$$

Since the left-hand side in (2.2) is independent of the particular choice of $n$ linearly independent solutions, the right-hand side must remain invariant under the transformation

$$
f_{i} \longrightarrow \frac{a_{i 0}+a_{i 1} f_{1}+\cdots+a_{i n-1} f_{n-1}}{b_{0}+b_{1} f_{1}+\cdots+b_{n-1} f_{n-1}}, i=1,2, \cdots, n-1,
$$

where the $a$ 's and $b$ 's are constants.

Theorem 2.1. Let $y_{i}, i=1,2, \cdots, n$, be linearly independent solutions of (2.1), let

$$
f_{1}=\frac{y_{1}}{y_{n}}, \cdots, f_{n-1}=\frac{y_{n-1}}{y_{n}}
$$


and let $W_{i}$ be the determinant defined by

$$
W_{i}=\left|\begin{array}{cccc}
f_{1}^{\prime} & f_{2}^{\prime} & \cdots & f_{n-1}^{\prime} \\
& \cdots & \\
f_{1}^{(i-1)} & f_{2}^{(i-1)} & \cdots & f_{n-1}^{(i-1)} \\
f_{1}^{(i+1)} & f_{2}^{(i+1)} & \cdots & f_{n-1}^{(i+1)} \\
& \cdots & & \\
f_{1}^{(n)} & f_{2}^{(n)} & \cdots & f_{n-1}^{(n)}
\end{array}\right|,
$$

$i=1,2, \cdots, n$. Then we have

(2.4) $\quad p_{i}=\frac{1}{W_{n} \sqrt[n]{W_{n}}}\left[\sum_{j=0}^{n-i}(-1)^{2 n-j}\left(1-\delta_{n j}\right)\left(\begin{array}{c}n-j \\ n-j-i\end{array}\right) W_{n-j}\left(\sqrt[n]{W_{n}}\right)^{(n-j \rightarrow i)}\right]$,

$i=0,1, \cdots, n-2$, where $\delta_{n n}=1$ and $\delta_{n j}=0$ otherwise.

Conversely, the general solution $\left(f_{1}, f_{2}, \cdots, f_{n-1}\right)$ of the system (2.4) of differential equations is of the form (2.3).

Proof. It is easily confirmed that $1, f_{1}, \cdots, f_{n-1}$ are linearly independent solutions of the differential equation

$$
y^{(n)}-\frac{W_{n-1}}{W_{n}} y^{(n-1)}+\cdots+(-1)^{n+1} \frac{W_{1}}{W_{n}} y^{\prime}=0
$$

and that $W_{n-1}=W_{n}^{\prime}$. Put

$$
y=Y \cdot \exp \left(\frac{1}{n} \int \frac{W_{n-1}}{W_{n}} d z\right)=Y \cdot \sqrt[n]{W_{n}} .
$$

Then the function $Y$ satisfies the differential equation

$$
Y^{(n)}+q_{n-2}(z) Y^{(n-2)}+\cdots+q_{0}(z) Y=0
$$

where

$$
q_{i}=\frac{1}{W_{n} \sqrt[n]{W_{n}}}\left[\sum_{j=0}^{n-i}(-1)^{2 n-j}\left(1-\delta_{n j}\right)\left(\begin{array}{c}
n-j \\
n-j-i
\end{array}\right) W_{n-j}\left(\sqrt[n]{W_{n}}\right)^{(n-j-i)}\right],
$$

$i=0,1, \cdots, n-2$. Furthermore, it is evident that

$$
\frac{f_{1}}{\sqrt[n]{W_{n}}}, \cdots, \frac{f_{n-1}}{\sqrt[n]{W_{n}}}, \frac{1}{\sqrt[n]{W_{n}}}
$$

are linearly independent solutions of (2.5).

We now assert that

$$
\frac{f_{1}}{\sqrt[n]{W_{n}}}=K y_{1}, \cdots, \frac{f_{n-1}}{\sqrt[n]{W_{n}}}=K y_{n-1}, \frac{1}{\sqrt[n]{W_{n}}}=K y_{n}
$$


for some constant $K$. But, if this assertion is true, it would imply that the differential equations (2.1) and (2.5) have the same set of linearly independent solutions $y_{1}, \cdots, y_{n}$. In other words, (2.1) and (2.5) are identical, i.e., $p_{i}=q_{i}, i=0,1, \cdots, n-2$, which proves the theorem. To prove the equalities in (2.6), it suffices to prove only the last equality. It is easily confirmed that

$$
(-1)^{n-1} W_{n}=\frac{W}{y_{n}^{n}},
$$

where $W$ is the Wronskian of $y_{1}, \cdots, y_{n}$ (see, e.g., [7]). Since the Wronskian $W$ is constant, we may set $K=-1 / \sqrt[n]{W}$ to obtain the last equality in (2.6).

The converse is easy to prove; it follows from the fact that

$$
\frac{f_{1}}{\sqrt[n]{W_{n}}}, \cdots, \frac{f_{n-1}}{\sqrt[n]{W_{n}}}, \frac{1}{\sqrt[n]{W_{n}}}
$$

are linearly independent solutions of (2.1).

For the second-order equation (1.1), the formulas in (2.4) yield the familiar relation (1.3); and for the third-order equation $y^{\prime \prime \prime}+p_{1}(z) y^{\prime}+$ $p_{0}(z) y=0$,

$$
\begin{gathered}
p_{0}=\frac{-1}{3}\left[\frac{2}{9}\left(\frac{f_{1}^{\prime} f_{2}^{\prime \prime \prime}-f_{1}^{\prime \prime \prime} f_{2}^{\prime}}{f_{1}^{\prime} f_{2}^{\prime \prime}-f_{1}^{\prime \prime} f_{2}^{\prime}}\right)^{3}-\left(\frac{f_{1}^{\prime} f_{2}^{\prime \prime \prime}-f_{1}^{\prime \prime \prime} f_{2}^{\prime}}{f_{1}^{\prime} f_{2}^{\prime \prime}-f_{1}^{\prime \prime} f_{2}^{\prime}}\right)^{\prime \prime}\right. \\
\left.-\left(\frac{f_{1}^{\prime} f_{2}^{\prime \prime \prime}-f_{1}^{\prime \prime \prime} f_{2}^{\prime}}{f_{1}^{\prime} f_{2}^{\prime \prime}-f_{1}^{\prime \prime} f_{2}^{\prime}}\right)\left(\frac{f_{1}^{\prime \prime} f_{2}^{\prime \prime \prime}-f_{1}^{\prime \prime \prime} f_{2}^{\prime \prime}}{f_{2}^{\prime} f_{2}^{\prime \prime}-f_{1}^{\prime \prime} f_{2}^{\prime}}\right)\right], \\
p_{1}=\frac{f_{1}^{\prime \prime} f_{2}^{\prime \prime \prime}-f_{1}^{\prime \prime \prime} f_{2}^{\prime \prime}}{f_{1}^{\prime} f_{2}^{\prime \prime}-f_{1}^{\prime \prime} f_{2}^{\prime}}+\left(\frac{f_{1}^{\prime} f_{2}^{\prime \prime \prime}-f_{1}^{\prime \prime \prime} f_{2}^{\prime}}{f_{1}^{\prime} f_{2}^{\prime \prime}-f_{1}^{\prime \prime} f_{2}^{\prime}}\right)^{\prime}-\frac{1}{3}\left(\frac{f_{1}^{\prime} f_{2}^{\prime \prime \prime}-f_{1}^{\prime \prime \prime} f_{2}^{\prime}}{f_{1}^{\prime} f_{2}^{\prime \prime}-f_{1}^{\prime \prime} f_{2}^{\prime}}\right)^{2} .
\end{gathered}
$$

3. Let $p_{0}, \cdots, p_{n-2}$ in (2.1) be analytic functions which are regular in a domain $D$ of the complex plane. The differential equation (2.1) is said to be disconjugate in $D$ if no nontrivial solution of (2.1) has more than $n-1$ zeros (where the zeros are counted with their multiplicities) in $D$. We now state an elementary principle which relates disconjugacy with a certain function-theoretic aspect of (2.1), as a theorem for convenient reference.

Theorem 3.1. Let $y_{1}, y_{2}, \cdots, y_{n}$ be linearly independent solutions of (2.1), and let $f_{i}=y_{i} / y_{n}, i=1,2, \cdots, n-1$. Then the differential equation (2.1) is disconjugate in $D$ if and only if every nontrivial linear combination of $f_{1}, f_{2}, \cdots, f_{n-1}$ is $(n-1)$-valent in $D$, i.e., it does not take on any one value more than $n-1$ times in $D$.

Proof. If (2.1) is not disconjugate in $D$, then there exists a 
nontrivial solution $y=\sum_{i=1}^{n} a_{i} y_{i}$, for some constants $a_{i} \neq 0, i=1,2, \cdots, n$, which has more than $n-1$ zeros in $D$. Without loss of generality, we may assume that none of the zeros of $y_{n}$ coincide with the zeros of $y$. Thus, we find that $a_{n}+\sum_{i=1}^{n-1} a_{i} f_{i}$ has more than $n-1$ zeros in $D$, i.e., the linear combination $\sum_{i=1}^{n-1} a_{i} f_{i}$ assumes the value $-a_{n}$ more than $n-1$ times in $D$. Conversely, if some nontrivial linear combination $\sum_{i=1}^{n-1} a_{i} f_{i}$ takes on the value $-a_{n}$ more than $n-1$ times in $D$, the nontrivial solution $y=\sum_{i=1}^{n} a_{i} y_{i}$ has more than $n-1$ zeros in $D$.

Next we shall establish a sufficient condition for disconjugacy of (2.1). We first require the following lemma.

LEMMA 3.1. Let $y$ be analytic in a region $R$. If $y\left(a_{i}\right)=0, a_{i} \in R$, $i=1,2, \cdots, n$, then

$$
y^{(k)}(z)=\sum_{j=1}^{k+1}\left(\begin{array}{c}
k \\
j-1
\end{array}\right) P_{n-j)}^{(k+1-j)}(z) I_{j}(z)\left(a_{j}-z\right)^{-j+1},
$$

$k=0,1, \cdots, n-1$, where

$$
\begin{gathered}
I_{n}(z)=\int_{a_{n}}^{z}\left(a_{n}-\zeta\right)^{n-1} y^{(n)}(\zeta) d \zeta, \\
I_{j}(z)=\int_{a_{j}}^{z} \frac{\left(a_{j}-\zeta\right)^{j-1}}{\left(a_{j+1}-\zeta\right)^{j+1}} I_{j+1}(\zeta) d \zeta, j=1,2, \cdots, n-1,
\end{gathered}
$$

and

$$
P_{n-j}(z)=\prod_{i=j+1}^{n}\left(a_{i}-z\right)
$$

Proof. It is easily confirmed that $y=P_{n-1} I_{1}$, which proves (3.1) for $k=0[1,3]$. The rest follows from induction on $k$.

We remark that the $a_{i}$ 's in the above lemma are not necessarily distinct; we may put $a_{k}=a_{k \div 1}=\cdots=a_{k \div m-1}$ if the $y$ has a zero of order $m$ at $a_{k}$.

THEOREM 3.2. Let $p_{0}, \cdots, p_{n-1}$ be analytic in the unit disk $D=$ $\{z:|z|<1\}$. If

$$
\sum_{k=1}^{n-1} \frac{(1+|z|)^{n-k}}{(n-k) !}\left|p_{k}(z)\right|+\frac{(1-|z|)(1+|z|)^{n-1}}{n !}\left|p_{0}(z)\right| \leqq 1,
$$

then the differential equation

$$
y^{(n)}+p_{n-1}(z) y^{(n-1)}+\cdots+p_{0}(z) y=0
$$

is disconjugate in $D$. 
Proof. Suppose that (3.3) has a nontrivial solution $y$ with $n$ zeros, i.e., $y\left(a_{i}\right)=0, a_{i} \in D, i=1,2, \cdots, n$. Then from Lemma 3.1 we have

$$
\begin{gathered}
y(z)=\left(a_{n}-z\right) \cdots\left(a_{2}-z\right) \int_{a_{1}}^{z} \frac{1}{\left(a_{2}-\zeta_{1}\right)^{2}} \int_{a_{2}}^{\zeta_{1}} \frac{a_{2}-\zeta_{2}}{\left(a_{3}-\zeta_{2}\right)^{3}} \\
\cdots \int_{a_{n-1}}^{\zeta_{n-2}} \frac{\left(a_{n-1}-\zeta_{n-1}\right)^{n-2}}{\left(a_{n}-\zeta_{n-1}\right)^{n}} \int_{a_{n}}^{\zeta_{n-1}}\left(a_{n}-\zeta_{n}\right)^{n-1} y^{(n)}\left(\zeta_{n}\right) d \zeta_{n} \cdots d \zeta_{1} .
\end{gathered}
$$

Let $H$ be the convex hull of $a_{1}, \cdots, a_{n}$. Since $\left|y^{(n)}(z)\right|$ is continuous in $H$, it attains its maximum in $H$ at some point $z=z_{0} \in H$. Taking the absolute values in (3.4) and performing the $n$-fold integration along the straight line segments connecting $a_{k}$ and $\zeta_{k-1}$, we arrive at

$$
\begin{aligned}
|y(z)| & \leqq \frac{1}{n !}\left|y^{(n)}\left(z_{0}\right)\right| \prod_{i=1}^{n}\left|a_{i}-z\right| \\
& <\frac{1}{n !}\left|y^{(n)}\left(z_{0}\right)\right|(1+|z|)^{n}, z \in H .
\end{aligned}
$$

Similarly,

$$
\left|y^{(k)}(z)\right|<\frac{(1+|z|)^{n-k}}{(n-k) !}\left|y^{(n)}\left(z_{0}\right)\right|, z \in H,
$$

$k=1,2, \cdots, n-1$. It is easily confirmed that

$$
\left|I_{j}\right| \leqq \frac{(j-1) !}{n !}\left|y^{(n)}\left(z_{0}\right)\right|\left|a_{j}-z\right|^{j},
$$

and that $P_{n-j}^{(k+1-j)}(z)$ is the sum of $(n-j) ! /(n-k-1)$ ! terms of the form $\prod_{l=1}^{n-k-1}\left(a_{i l}-z\right)$. Therefore, we obtain from (3.1)

$$
\begin{aligned}
\left|y^{(k)}(z)\right| & <\left|y^{(n)}\left(z_{0}\right)\right| \sum_{j=1}^{k+1}\left(\begin{array}{c}
k \\
j-1
\end{array}\right) \frac{(n-j) !}{(n-k-1) !} \frac{(j-1) !}{n !}(1+|z|)^{n-k} \\
& =\frac{(1+|z|)^{n-k}}{(n-k) !}\left|y^{(n)}\left(z_{0}\right)\right|, z \in H,
\end{aligned}
$$

which proves (3.6).

We remark that the second inequality in (3.5) may be improved; by a result of Schwarz [8],

$$
\prod_{i=1}^{n}\left|a_{i}-z\right|<(1-|z|)(1+|z|)^{n-1}, z \in H,
$$

and therefore

$$
|y(z)|<\frac{1}{n !}(1-|z|)(1+|z|)^{n-1}\left|y^{(n)}\left(z_{0}\right)\right|, z \in H .
$$


Finally, we deduce from (3.3), (3.6), and (3.7) that

$$
\begin{aligned}
\left|y^{(n)}(z)\right|<\left|y^{(n)}\left(z_{0}\right)\right| & {\left[\sum_{k=1}^{n-1} \frac{(1+|z|)^{n-k}}{(n-k) !}\left|p_{k}(z)\right|\right.} \\
+ & \left.\frac{1}{n !}(1-|z|)(1+|z|)^{n-1}\left|p_{0}(z)\right|\right], z \in H,
\end{aligned}
$$

which, for $z=z_{0} \in H$, yields

$$
1<\sum_{k=1}^{n-1} \frac{\left(1+\left|z_{0}\right|\right)^{n-k}}{(n-k) !}\left|p_{k}\left(z_{0}\right)\right|+\frac{1}{n !}\left(1-\left|z_{0}\right|\right)\left(1+\left|z_{0}\right|\right)^{n-1}\left|p_{0}\left(z_{0}\right)\right|,
$$

contrary to (3.2). This contradiction proves the theorem.

We add two remarks. A slight modification of the above proof will establish the following statements: Let $R$ be a convex region with diameter $\delta$. If

$$
\sum_{k=0}^{n-1} \frac{\delta^{n-k}}{(n-k) !}\left|p_{k}(z)\right| \leqq 1, z \in R,
$$

then (3.3) is disconjugate in $R$. Theorem 3.2 generalizes a result recently obtained by Hadass [2, Th. 2].

There are known to the author a few other disconjugacy criteria for higher-order equations with analytic coefficients [4, 6].

We are now ready to state the disconjugacy condition (Theorem 3.2) as a multivalence criterion. From Theorems 2.1 and 3.1 we see that every nontrivial linear combination of $f_{1}, f_{2}, \cdots, f_{n-1}$ is $(n-1)$ valent if the equation

$$
y^{(n)}+p_{n-2}(z) y^{(n-2)}+\cdots+p_{0}(z) y=0,
$$

where $p_{0}, \cdots, p_{n-2}$ are defined as in (2.4), is disconjugate. In view of this relation and Theorem 3.2, we have the following theorem.

THEOREM 3.3. Let $f_{1}, f_{2}, \cdots, f_{n-1}$ be analytic in the unit disk $D=\{z:|z|<1\}$. Define $p_{0}, p_{1}, \cdots, p_{n-2}$ as in (2.4). If $\operatorname{det}\left(f_{j}^{(i)}\right)_{i, j=1}^{n-1}$ does not vanish in $D$, and if

$$
\begin{aligned}
& \sum_{k=1}^{n-2} \frac{(1+|z|)^{n-k}}{(n-k) !}\left|p_{k}(z)\right| \\
& \quad+\frac{1}{n !}(1-|z|)(1+|z|)^{n-1}\left|p_{0}(z)\right| \leqq 1, z \in D,
\end{aligned}
$$

then every nontrivial linear combination of $f_{1}, f_{2}, \cdots, f_{n-1}$ is $(n-1)$ valent in $D$. 


\section{REFERENCES}

1. G. A. Bessmertnyh and A. Yu. Levin, Some inequalities satisfied by differentiable functions of one variable, Dokl. Akad. Nauk SSSR 144 (1962), 471-474. (Translation: Soviet Math. Dokl. 3 (1962), 737-740).

2. R. Hadass, On the zeros of the solutions of the differential equation $y^{(n)}(z)+p(z) y(z)=$ 0, (to appear in the Pacific J. Math.)

3. W. J. Kim, On a theorem of Pokornyi, (to appear in the Proc. Amer. Math. Soc.) 4. M. Lavie, The Schwarzian derivative and disconjugacy of $n^{\text {th }}$-order linear differential equations, Canad. J. Math. 21 (1969), 235-249.

5. Z. Nehari, The Schwarzian derivative and schlicht functions, Bull. Amer. Math. Soc. 55 (1949), 545-551.

6. - On the zeros of solutions of $n$-th order linear differential equations J. London Math. Soc. 39 (1964), 327-332.

7. G. Pólya and G. Szegö, Aufgaben und Lehrsätze aus der Analysis, Vol. II, SpringerVerlag, Belrin, 1964, p. 113.

8. B. Schwarz, On the product of the distance of a point from the vertices of a polytope, Israel J. Math. 3 (1965), 29-38.

9. V. Vodička, Verallgemeinerung einer Schwarzschen Differentialgleichung, Monatsh. Math. 67 (1963), 137-141.

Received May 28, 1969.

State UNiversity OF NeW YoRk

StONY BROOK, NeW YoRK 


\title{
PACIFIC JOURNAL OF MATHEMATICS
}

\author{
EDITORS
}

\author{
H. ROYDEN \\ Stanford University \\ Stanford, California \\ RICHARD PIERCE \\ University of Washington \\ Seattle, Washington 98105
}

\author{
J. DUGUNDJI \\ Department of Mathematics \\ University of Southern California \\ Los Angeles, California 90007 \\ BASIL GORDON \\ University of California \\ Los Angeles, California 90024
}

\section{ASSOCIATE EDITORS}

E. F. BECKENBACH
B. H. NeumanN

F. WOLF
K. YoshidA

\section{SUPPORTING INSTITUTIONS}

\author{
UNIVERSITY OF BRITISH COLUMBIA \\ CALIFORNIA INSTITUTE OF TECHNOLOGY \\ UNIVERSITY OF CALIFORNIA \\ MONTANA STATE UNIVERSITY \\ UNIVERSITY OF NEVADA \\ NEW MEXICO STATE UNIVERSITY \\ OREGON STATE UNIVERSITY \\ UNIVERSITY OF OREGON \\ OSAKA UNIVERSITY \\ UNIVERSITY OF SOUTHERN CALIFORNIA
}

\author{
STANFORD UNIVERSITY \\ UNIVERSITY OF TOKYO \\ UNIVERSITY OF UTAH \\ WASHINGTON STATE UNIVERSITY \\ UNIVERSITY OF WASHINGTON

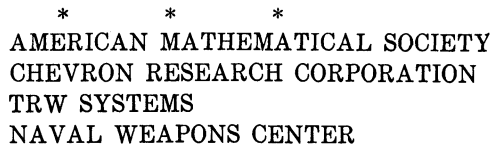

The Supporting Institutions listed above contribute to the cost of publication of this Journal, but they are not owners or publishers and have no responsibility for its content or policies.

Mathematical papers intended for publication in the Pacific Journal of Mathematics should be in typed form or offset-reproduced, double spaced with large margins. Underline Greek letters in red, German in green, and script in blue. The first paragraph or two must be capable of being used separately as a synopsis of the entire paper. It should not contain references to the bibliography. Manuscripts, in duplicate if possible, may be sent to any one of the four editors. Please classify according to the scheme of Math. Rev. 36, 1539-1546. All other communications to the editors should be addressed to the managing editor, Richard Arens, University of California, Los Angeles, California, 90024.

50 reprints are provided free for each article; additional copies may be obtained at cost in multiples of 50 .

The Pacific Journal of Mathematics is published monthly. Effective with Volume 16 the price per volume (3 numbers) is $\$ 8.00$; single issues, $\$ 3.00$. Special price for current issues to individual faculty members of supporting institutions and to individual members of the American Mathematical Society: $\$ 4.00$ per volume; single issues $\$ 1.50$. Back numbers are available.

Subscriptions, orders for back numbers, and changes of address should be sent to Pacific Journal of Mathematics, 103 Highland Boulevard, Berkeley, California, 94708.

PUBLISHED BY PACIFIC JOURNAL OF MATHEMATICS, A NON-PROFIT CORPORATION

Printed at Kokusai Bunken Insatsusha (International Academic Printing Co., Ltd.), 7-17, Fujimi 2-chome, Chiyoda-ku, Tokyo, Japan. 


\section{Pacific Journal of Mathematics}

\section{Vol. 31, No. $3 \quad$ BadMonth, 1969}

George E. Andrews, On a calculus of partition functions .................. 555

Silvio Aurora, A representation theorem for certain connected rings ............ 563

Lawrence Wasson Baggett, A note on groups with finite dual spaces ............. 569

Steven Barry Bank, On majorants for solutions of algebraic differential equations in regions of the complex plane ............................... 573

Klaus R. Bichteler, Locally compact topologies on a group and the corresponding continuous irreducible representations ......................... 583

Mario Borelli, Affine complements of divisors ....................... 595

Carlos Jorge Do Rego Borges, A study of absolute extensor spaces ............. 609

Bruce Langworthy Chalmers, Subspace kernels and minimum problems in Hilbert

spaces with kernel function ...................................... 619

John Dauns, Representation of L-groups and F-rings................. 629

Spencer Ernest Dickson and Kent Ralph Fuller, Algebras for which every

indecomposable right module is invariant in its injective envelope ...........

Robert Fraser and Sam Bernard Nadler, Jr., Sequences of contractive maps and fixed

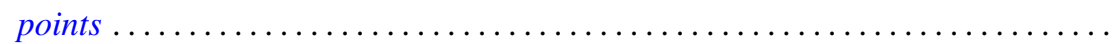

Judith Lee Gersting, A rate of growth criterion for universality of regressive

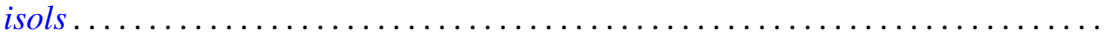

Robert Fred Gordon, Rings in which minimal left ideals are projective ............

Fred Gross, Entire functions of several variables with algebraic derivatives at certain algebraic points

W. Charles (Wilbur) Holland Jr. and Stephen H. McCleary, Wreath products of ordered permutation groups .........................

W. J. Kim, The Schwarzian derivative and multivalence .................. 717

Robert Hamor La Grange, Jr., On $(\mathrm{m}-\mathrm{n})$ products of Boolean algebras ......... 725

Charles D. Masiello, The average of a gauge ........................ 733

Stephen H. McCleary, The closed prime subgroups of certain ordered permutation

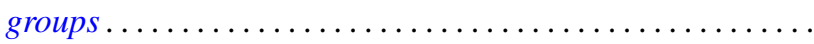

Richard Roy Miller, Gleason parts and Choquet boundary points in convolution measure algebras ...............................

Harold L. Peterson, Jr., On dyadic subspaces ........................ 773

Derek J. S. Robinson, Groups which are minimal with respect to normality being intransitive........................................... 777

Ralph Edwin Showalter, Partial differential equations of Sobolev-Galpern type . . . 787

David Slepian, The content of some extreme simplexes ................... 795

Joseph L. Taylor, Noncommutative convolution measure algebras ............. 809

B. S. Yadav, Contractions of functions and their Fourier series ............... 827

Lindsay Nathan Childs and Frank Rimi DeMeyer, Correction to automorphisms of separable algebras" ....................... 833

Moses Glasner and Richard Emanuel Katz, Correction to: "Function-theoretic degeneracy criteria for Riemannian manifolds".............

Satish Shirali, Correction to: "On the Jordan structure of complex Banach

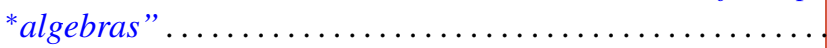

